\title{
6 Work, Technology, and Inequality
}

\author{
Kory P. Schaff
}

Recent technological innovation in microchip processors, robotics, and artificial intelligence has the potential to create a perfect storm that radically transforms the structure and organization of work. In particular, the rise of "smart" machines on assembly lines, delivery drones, and self-driving vehicles are likely to eliminate many kinds of jobs in the near future. ${ }^{1}$ The prospect of such changes raises serious concerns about the impact of technology on human values and what will happen to the welfare of millions of workers whose livelihoods are rendered obsolete. At the same time, democratic welfare states continue to struggle with inequality in many spaces, including education, gender and racial discrimination, unemployment and stagnant wages, poverty, and wealth disparity. These problems have also been intensified by technology and globalization. Despite an unprecedented expansion of access to information and communication the digital revolution has made possible, inequality in developed countries is at record levels, and the gap with developing countries grows wider (Pikkety 2014).

Given these developments, a novel proposal that is the subject of debate among both academics and policymakers is now gaining fresh momentum: Provide all citizens with a "basic income" that ensures a social minimum. The strategy of this proposal is to give all qualified individuals an unrestricted cash grant that provides them with all-purpose means that do not depend on status, wealth, or employment. Without restrictions, individuals can choose for themselves how best to utilize the grant. Some of these choices may include reducing work hours, increasing leisure time, investing in financial markets, creating small businesses, or consuming more goods. The creation of this social minimum might also alleviate some of the problems of inequality just described. For example, the automation of workplaces will mean fewer jobs in the future, so the provision of a basic income could be an efficient solution to a rather complex set of problems.

Can basic income replace work in the age of automation? More specifically, we want to know whether a basic income scheme can replace the benefits of work in an age where technology has the potential to 
eliminate work altogether. Work has financial and non-pecuniary benefits. While it provides individuals with an income to satisfy their needs, it also has benefits in the form of self-realization, self-respect, and community. However, work also entails various burdens in the form of low wages, overwork, and diminished autonomy. The provision of a universal cash grant can supplement the financial benefits of work by giving individuals flexible means to maximize their choices and achieve their goals. To the extent it is used to reduce work hours in favor of leisure, or expand occupational choice, basic income can improve the welfare of its beneficiaries. There is still the question whether such a grant can replace the non-pecuniary benefits of work. To answer the question, we shall investigate these overlapping areas of concern, which are the benefits and burdens of work, the effects of technology on work and welfare, the benefits of basic income, and the limits of this scheme for a social minimum.

The first section examines the benefits and burdens of work, drawing a distinction between its financial and non-pecuniary benefits in the form of self-realization, self-respect, and community. In the second section, the effects of technology on work are considered. Although innovation can improve efficiency, and has the potential to enhance welfare for this reason, the effect of this process has been the intensification of labor and, ultimately, its obsolescence. For this reason, the automation of work does have significant costs to the welfare of workers, and these ought to be weighed against its potential benefits in the future. The third section examines the arguments for a basic income that make it a philosophically attractive alternative to traditional welfare policies. One reason is that a universal cash grant avoids some classical objections to the welfare state including that of paternalism and "free riding." A basic income scheme might be a clever way of avoiding these problems, but without addressing the structure of property relations that gives rise to them, it is doubtful it can reduce inequality. Finally, the last section focuses on the question whether the benefits of basic income can replace the loss of work caused by automation and obsolescence. Even though it can augment the financial benefits of work, or supplement their loss, a cash grant by itself cannot replace its non-pecuniary benefits.

\section{The Benefits and Burdens of Work}

The value of work is defined by two recurring themes historically. The first emerges from the Reformation and has the optimistic view that work is a good for individuals. In his classic study of it, Max Weber argues the "protestant ethic," which is composed of hard work and deferred gratification among other things, is the "spirit" that animates modern capitalism. He claims that part of what makes this mode of production distinct from past forms of accumulation is "the rational capitalistic organization of formally free labour." In combination with "the separation of business 


\section{Kory P. Schaff}

from the household" and "rational book-keeping," capitalism allows individuals to pursue their self-interest while promoting the welfare of others (Weber 1930: xxxv). In this respect, the work ethic also fulfills a divine command to do "good works and deeds" in this life. The second theme is far older and pessimistic: Work is a burden suited for lesser men, or even punishment imposed on humans for violating divine law. The first belief figures in Greco-Roman thought, which holds that the highest good of contemplation is opposed to physical toil and justifies the hierarchy of the polis that is built on slave labor. The second can be found in Judeo-Christian thought from the Book of Genesis to the writings of St. Augustine and beyond. Taken together, the themes that work can be a force for good as well as burdensome alternatively figure in our own understanding of work. ${ }^{2}$

Let us start by considering the benefits of work. In a market economy, work is an activity requiring the time and labor power of individuals who receive compensation for it. Work has obvious benefits that are instrumental for this reason. With the compensation earned from work, individuals have the means to satisfy their needs and create financial stability to make future plans including retirement. The value is instrumental because work is a mere means to other ends. By providing universal means in the form of money, which can be used to buy goods or invest in their own social capital, individuals exercise their autonomy, make choices about how to prioritize needs, and satisfy their desires. One might object that work has no value in itself for this very reason. If it has instrumental value only because it provides individuals with an income, then these means have value and not work. [This raises a question about basic income and whether individuals will work if they are provided with other means that do not depend on gainful employment. We shall return to this question later, when we examine the benefits of basic income and whether they can replace work.]

There are other benefits to work that are not instrumental. These include the role it plays in the self-realization of individuals, the selfrespect they gain from it, and the sense of community it fosters. What role does work play in terms of self-realization? Jon Elster defines it as "the self-externalization and self-actualizing deployment of one's powers and abilities" (Elster 1988: 66). He claims that self-realization is not only the most important work-related value, but also its most peripheral for the following reason: In market economies, production is decentralized, so there are many job opportunities for individuals to choose from. This decentralization also means "that working conditions for most people in contemporary industrial societies-capitalist and communist-do not lend themselves to fulfillment of this goal" (Elster 1988: 66). So work has the potential to promote individual self-realization, but this is frustrated by the fact that most work in market economies does not require much of individuals in terms of their capacities. However, the lack of fit between 
"self-realization" as Elster defines it, and opportunities for work that can realize it, suggests that the standard here might be set too high. ${ }^{3}$

What do "powers and abilities" mean in this context, and how do they realize the self? Arguably, all work involves the use of these capacities since any activity requiring the use of labor power to produce goods or provide services entails the use of at least some of these. To be sure, there are "powers and abilities" such as mathematical skills that are more complex and deliberative and that require more education. These are typically rewarded with more compensation than skills that are simple and non-deliberative. However, the difference between these skill sets is not a binary, at least where the "deployment of powers and abilities" is concerned. The difference is rather one of degree. The concepts of "complexity" and "simplicity" are continuous and admit of more or less degrees when applied to skills that are utilized for work. So making or doing something of any kind requires using "powers and abilities" whether these are more or less skilled. It seems to be a mistake, then, to claim that the value of self-realization found in work is peripheral because there are few opportunities for work that fulfills this goal. The problem with Elster's conclusion is its implicit perfectionist assumption about the "powers and abilities" that compose the self. He conceives of an ideal "self" with the potential for robust capacities, which are wasted in work that requires less knowledge and skills. The implicit ranking of skills depends on the view that all individuals should strive to realize their greatest potential in highly skilled work. Since only some can do this in market economies, that standard is self-defeating. So the self-realization that work offers should be agnostic about ranking "powers and abilities" in perfectionist terms. Instead, we should affirm a minimal but still significant sense in which work promotes self-realization, simply because in making or doing something, individuals are externalizing their capacities, whatever those happen to be.

Another benefit of work is that individuals gain self-respect from it. John Rawls claims that self-respect consists of "a person's sense of his own value" and "confidence in one's ability to fulfil one's intentions" (Rawls 1999: 386). If we take these features in combination, work should give individuals a sense of worth and confidence they can achieve their goals. Ostensibly, work does measure a sense of worth because of its compensation. From the viewpoint of the labor market, individuals literally have a value placed on them by being paid for their time and labor power. This cannot be the basis of worth described by Rawls, however. We must be careful not to imply some individuals are worth more than others simply on the basis of the size of their income. From the moral point of view, the lives of all individuals have equal worth, so the monetary value of work cannot be its source of worth. Instead, it must foster a sense of value that is not merely about money, but about something else. ${ }^{4}$ Work contributes to a person's sense of worth in at least two other ways. The first is that 


\section{Kory P. Schaff}

individuals gain satisfaction from making or doing something that utilizes their labor power. Using their time and skills to produce goods and services that others require or desire can be a satisfying endeavor itself. ${ }^{5}$ A second way that work fosters self-respect is because it is a social activity that involves cooperation with others. This is a crucial source for a sense of worth since all of our interactions with others are structured by mutual recognition. Individuals depend on one another for achieving the self-satisfaction of knowing that others regard their actions or interests as having value. This is not just a question of having a sense a worth because one feels useful to others, though as studies of workers and unemployment show, this is part of the reason why work fosters selfrespect. ${ }^{6}$ Work also entails other kinds of social interaction that support a sense of worth. These include camaraderie, friendships, water cooler gossip, teamwork, and even a sense of belonging to a community, which can also be found in different forms of association as well.

What about the second part of self-respect regarding "confidence" that individuals can achieve their goals? Work builds confidence in various ways. First, utilizing one's power and abilities to achieve a personal or common goal is essential for gaining confidence. By committing to some task and accomplishing it, individuals affirm their own capacities to achieve it. The use of their talents, skills, and education all figure in this respect. Even low-skill jobs that lack the use of deliberation require individuals to select the proper means for realizing the ends that are constitutive of the work. Moreover, research shows that on-the-job training for low-skill jobs does build confidence and develops human capital in the form of commitment, time management, responsibility, and other qualities that are useful at work and beyond. ${ }^{7}$ Work also promotes confidence through social interaction, which is crucial for affirming our sense of how well we are doing. Since it is a form of social cooperation, confidence is shaped by feedback from employers, co-workers, clients, and customers alike. This is why modern workplaces are organized by procedures of assessment and evaluation-to ensure individuals are doing the tasks required by the job and to improve on the execution of those tasks. Taken together, the exercise of "powers and abilities" in the context of social interaction with other promotes self-respect, in terms of an individual developing her own sense of worth and the confidence she gains from it.

Finally, work has value because it fosters community. This is both an individual and collective good in the following sense. When individuals are engaged in common projects that most work entails, they commit to them as individuals and help to realize those projects as members of an association. If such a commitment is voluntary, then work is good for individuals in all the senses described earlier. It promotes their selfrealization because they must deploy their capacities to produce some good or service, and it fosters self-respect because they gain a sense of worth and build confidence that they can realize their ends. There is 
competition in the labor market, of course, where individuals compete against others for positions and promotions. This does not mean, however, that competition exclusively defines work. There can be healthy competition that pushes individuals to achieve excellence or otherwise excel at whatever talents and skills they happen to have. This also benefits others who rely on their use of such talents and skills. Furthermore, the conditions of interdependence found in work signal that there is also a collective good that is achieved as well. While it does require engaging in common projects that benefit both individuals and communities, from the collective viewpoint work also promotes forms of mutual recognition such as assurance, trust, and empathy. These are essential for the stability and reproduction of the social life of a community, and they give purpose and meaning to the work that individuals do in their communities.

Now we can consider a serious objection to the idea that work has value other than providing individuals with the means to satisfy their needs and achieve their ends. Some philosophers reject the claim that work is a good in itself because that assumes an essentialist conception of work that amounts to paternalism about what is good for all individuals. Andrew Levine makes a novel argument for a right not to work in this respect. In a paper titled "Fairness to Idleness," he claims the liberal commitment to state neutrality regarding conceptions of the good must permit individuals to pursue their own good without favoring one particular view over another (Levine 2001). For this reason, an individual's conception of the good that eschews work must be given the same weight of consideration as an individual who prefers to work. The neutrality thesis can be construed along these lines to require the democratic state to provide individuals with basic goods so they can pursue whatever ends they adopt, even if these ends are otherwise thought to be unproductive. In effect, neutrality toward the good supports a right to leisure against the paternalist principle that it is good for individuals to work and support themselves. This means individuals can decide work is not good for them, preferring instead to "count blades of grass on the courthouse lawn" or take up surfing as a way of life (Rawls 1999: 432). Thus, work has no value in itself unless individuals determine that it is good for them.

One way to respond to this objection is to show that the benefits of work just described do not logically entail paternalism about what is good for individuals. With respect to self-realization, we have seen that that the "powers and abilities" required for work need not be deliberative and require complex skills. The conception that these capacities should be deliberative and skilled in order to realize a robust self depends on perfectionist principles that we can do without. Whether it involves highly complex skills requiring an advanced education or digging trenches for sewer lines, all individuals utilize their capacities of labor power at work. The intuition that "brain work" is better for realizing the self than "dirty work" misses the point that all work is the externalization of human 


\section{Kory P. Schaff}

capacities in the service of some end. This line of reasoning applies to self-respect and community as well. Individuals in so-called menial jobs are no less entitled to a sense of worth and confidence that they get from a job well done. Work does not impart self-respect because only the best kinds of "powers and abilities" it requires are things worthy of respect. As we have shown, much of the value that work imparts depends on taking into consideration two things: whether the work itself is done well, and whether there are others who recognize that. Indeed, the fact that work depends on social interaction is a significant reason why it fosters self-respect and community. Without the mutual recognition that gives structure to our forms of social interaction, it is hard to conceive of values like self-respect and community having any meaning at all. So it cannot be the case that work has nothing but instrumental value for individuals, because value is determined in the context of inter-subjective relations with others. The non-pecuniary value of work does not require paternalism about deciding what is good for individuals, then, only that it is a good thing for individuals to have social interaction that is a rich source of meaning for their own lives. For most individuals, work is that daily venue where this interaction takes place, though it is not and need not be the only such venue.

What about the burdens of work? These burdens include instrumentalism, exploitation and coercion, and diminished autonomy. Again, the instrumental value of work gives individuals an income that is the means to satisfy their needs and pursue their goals. This is external to the work itself and employers make provision for it. For this same reason, work can also be a burden when it fails to provide enough means for individuals to meet needs and support pursuits. The elasticity here suggests that its instrumental benefits are only as good as they are sufficient to satisfy basic needs and allow individuals to pursue their life plans. If work fails to provide enough income to do these things, it easily turns into a burden that is all-too-familiar for those working multiple jobs to make ends meet. Indeed, the costs associated with financial instability found among the working poor are serious, including the decline of health and economic indicators (Singer and Ryff 2001: Ch. 7). The double-edged nature of this instrumental value suggests that a minimum wage policy is better than no policy at all, but that something like a living wage policy might be the best way to maximize the instrumental benefits of work (Pollin and Luce 2000).

An additional burden of work is the problems of exploitation and coercion. These are concerned with the voluntariness of conditions in which agreements between employers and workers are made. From the moral point of view, exploitation occurs whenever one agent uses another merely as a means, whereas coercion involves persuading an agent to do something by using force or threats. In the nineteenth century, Bruno Bauer and Karl Marx helped to popularize the criticism that capitalism 
exploits workers (Breckman 1999). Marx's theory of exploitation is that unequal property relations between owners of the means of production and the proletariat enables the former to use the latter for the creation of profit, since they pay wages that are far less than the exchange-value of the products created by workers (Marx 1844: 324-25). More recently, philosophers have examined the problem of coercion regarding labor to determine whether employment offers count as instances of coercion. Robert Nozick argues that coercion occurs when one agent attempts to induce another to act by means of a threat (Nozick 1974). What distinguishes a threat from other kinds of offers is the allegation that there will be consequences attached to the recipient if she does not alter her course of action accordingly. On this basis, offers of employment in the labor market are not supposedly coercive, because there are no threats attached to it. If an individual does not like the offer for work, she simply moves along to consider further prospective offers. However, other philosophers argue that wage offers can still be coercive despite the absence of explicit threats. David Zimmerman claims that an offer is coercive under the following conditions: "(1) an alternative pre-proposal situation workers would strongly prefer to the actual one is technologically or economically feasible when the offer is made, and (2) capitalists prevent workers from having at least one of these feasible alternative pre-proposal situations" (Zimmerman 1981: 145). On this view, workers are still coerced to accept employment offers because they have no access to better preoffer proposals, and property relations under capitalism give employers both material and non-material resources to restrict the availability of such alternatives.

We cannot resolve these problems by evaluating the arguments found in an extensive literature. ${ }^{8}$ Rather, the point here is to highlight that there are conditions of "social unfreedom" relating to the value of work as a voluntary choice that must be considered (Ezorksy 2007: 9). Setting aside for the moment any substantial differences between exploitation and coercion, it is clear that work poses some constraints on autonomy. After all, without inheritance or other sources of income, most individuals are obliged to find (and keep) paid work in the labor market. Doing so is what gives them independence and self-sufficiency, features we typically associate with what it means to live a free life. Without work, they have to rely on others such as family, friends, churches, or the state to satisfy their needs, which is a condition of dependence that is the opposite of living a free life. Questions about whether capitalism is exploitative, or whether offers for work are coercive in the absence of threats, are narrowly tailored and can miss the broader context of these social and political relations influencing our work lives. At one level, individuals are apparently free to choose from different offers for work (assuming there are more jobs than workers looking for them). As we have pointed out, this is one set of alternatives, the structure and consequences of which 
tend to exclude rational consideration of the alternative not to work. So workers are "unfree" in a sense as well. They cannot consider that alternative because the consequences of choosing it either expose them to the harms of depravation or commit them to dependence on others. These harms are widely confirmed by studies of workers dealing with job loss, which show that they suffer from severe and chronic medical problems ranging from self-doubt and depression to loss of sex drive and suicide (Uchitelle 2006: Ch. 8).

Finally, work is also a burden because it diminishes autonomy. For almost all workers in market economies, the structure and organization of work is anti-democratic. We can illuminate this problem by summarizing the "parallel case" argument comparing the similarities of democratic states and market firms:

[W] henever individuals cooperate together in a rule-governed common enterprise that should work to their common advantage, they all have the right to participate by way of majority-rule procedure in making the association rules, provided all have the capacity to do so. The political order and the economic firm are both common enterprises in the relevant respects, so the right to democratic citizenship applies equally in both arenas.

(Arneson 1993: 139)

Since most firms are organized vertically so that decision-making is centralized under executive management, workers are prevented from participating in decisions affecting their interests. One argument in favor of this hierarchical form emphasizes its economic efficiency, citing the need for responsiveness to quickly changing market conditions and the expertise required for reading these changes. There are clearly costs associated with this form of work as well, including lack of autonomy, transparency, and accountability that come with centralized decisionmaking. Whether such trade-offs are justified by the alleged efficiency of such arrangements, or whether there are alternatives that can fulfill these values and maintain economic efficiency, is beyond the scope of our present concerns. ${ }^{9}$ We cannot settle this debate here, but that is not essential for a brief review of the claim that anti-democratic work can be a burden.

There is something insightful about the "parallel case" argument. The purpose of the democratic state is to secure individuals liberty by making provisions for self-government and protecting their property rights. By contrast, the purpose of markets is to set prices on goods and services on the basis of the principles of supply and demand, and permit both producers and consumers to pursue their own ends accordingly. In the former, participation is guaranteed equally by citizenship that is protected by the right to vote, public offices that are open to all, and 
protection of rights to free speech and association. In the latter, there is no guarantee for equal participation because the principal entry point in the market is finding work, but there is no right to it in the form of guaranteed employment. ${ }^{10}$ Nevertheless, having and keeping work is thought to be essential for living a free life, because without it individuals cannot satisfy their own needs and must depend on others. To the extent that work is organized on the basis of democratic values, it appears to provide more opportunities for work that can enhance these benefits. However, if it is organized exclusively on the basis of profitability and efficiency, and serves anti-democratic outcomes such as suppressing the choices of workers for better alternatives, then it clearly frustrates the values of selfrealization, self-respect, and community.

\section{Technology, Automation, and Obsolescence}

Philosophers have long reflected on the relationship of technology and labor. Both Plato and Aristotle claim that "practical action" (phrónēsis) and "craftsmanship" (téchne) play substantial roles in the acquisition of knowledge, virtue, and the highest good. In the twentieth century, Martin Heidegger and Herbert Marcuse contend that modern technology objectifies the world to the detriment of human flourishing. The latter, more pessimistic, view resonated in particular among those who survived the death and destruction of both the First and Second World War. Before considering the effects of technology on work, we should pause to consider this more fundamental question of how technology itself ought to be evaluated.

There are two competing theories here-instrumentalism and substantivism. The first defends a view widely shared by governments, technocrats, and policymakers that technology is value-neutral because it is merely a means to achieve ends that are external to it. As a means, it can have no value in itself because only those agents who wield it can have values. The second claims technology "constitutes a new cultural system that restructures the entire social world as an object of control" (Feenberg 2002: 6). On this view, means and ends are deeply intertwined, so that the former inevitably embodies values that influence and shape the latter. Whether technology is value-neutral is not our focus per se. If it is neutral, its effects on work will be determined by the values of agents utilizing them, but if not, its effects will be determined by values it embodies in its design and implementation. The purpose of introducing these theories is that they provide different conceptual resources for evaluating the effects of technology on work. This is the case in terms of its instrumental effects, as well as the profound influence that technology has in shaping the ends of those agents who use it.

What about the effects of technology on work? First, it has significant effects on work when applied to methods of production because it 
utilizes resources more efficiently and increases the productivity of labor. Adam Smith made this observation a basic part of his theory of economic development:

This great increase of the quantity of work, which, in consequence of the division of labour, the same number of people are capable of performing, is owing to three different circumstances; first, to the increase of dexterity in every particular workman; secondly, to the saving of the time which is commonly lost in passing from one species of work to another; and lastly, to the invention of a great number of machines which facilitate and abridge labour, and enable one man to do the work of many.

(Smith 1776: 11)

The introduction of machines and innovation of new techniques for production helps to alleviate work comprised of physical, redundant, and dangerous tasks. This saves time for workers by reducing the need for labor power but also protects their health and longevity by mediating between them and harmful work. Technology also facilitates the specialization of labor in this regard. The increase of innovation creates new kinds of work for it in the division of labor. With this specialization arises new and expanded opportunities for the development of social capital in the form of skills, training, and education. The development of this social capital spurs further innovation and specialization, thereby completing the dynamic loop of development and wealth that supposedly "lifts all boats with the rising tide." 11 Moreover, technology can also expand opportunities for leisure. Since it creates more wealth, it can be used to improve the use of income that is earned from work. For example, with a reduction in the necessary labor time, individuals have more time to enjoy activities that do not require them to use their labor power.

The effects of technology on work are not always optimal, however. We noted in the last section that the instrumental value of work cuts both ways, so to speak, in terms of its benefits and burdens. Although work provides individuals with the benefit of an income, it is a burden if that income is not adequate to satisfy needs and pursue a life plan. Technology is similar in this respect. While its effects can improve the benefits of work, it can also exacerbate its burdens. An example of this "Catch-22" is the propensity it has to increase productivity and create overwork at the same time. In her study The Overworked American, the economist Juliet Schor describes the problem this way:

Productivity measures the goods and services that result from each hour worked. When productivity rises, a worker can either produce the current output in less time, or remain at work the same number of hours and produce more. Every time productivity increases, we 
are presented with the possibility of either more free time or more money. That's the productivity dividend.

(Schor 1991: 2)

She discovers a significant trend in the American economy that started in 1948 and continues today. During this time, the pace of innovation occurred steadily while productivity more than doubled, so we can now produce a 1948 standard of living with less than half the work hours needed in that year. However, nothing of that productivity dividend led to decreased work hours and increased leisure. Americans now work more and longer hours than they have at any time in the past. We might explain this trade-off in terms of instrumentalism: Technology did not cause the burden of increased work hours because it is value-neutral. To determine the cause of overwork, we would have to look closer at the actions of the agents employing the technology. The failure of workers to capitalize on this dividend by taking more leisure time might, therefore, be attributed to the values of agents and not the technology itself. For economists, this outcome merely signals that workers themselves prefer to increase income rather than take more leisure. However, a more likely explanation seems to be that weak labor laws, coupled with declining participation in unions, helped suppress the alternative choice of taking more leisure time.

To understand the imperatives that govern technology and shape the ends of agents, we need to understand that the structure of modern capitalism is composed of private ownership over the means of production, wage labor, and expansion of technology. As Weber noted, perhaps its most distinctive feature is "rationally organized labor." This rationality is instrumental because the price of wage labor is determined by the market principles of supply and demand. As a result, the structure of capitalist property relations contributes to the alienation of workers by treating them as variables in the calculation of profit. According to Marx, workers do not own either the resources they use or the commodities they produce with them and become estranged from themselves and one another as a result (Marx 1844: 63-64). Under these conditions, the productivity of labor is intensified and alternatives for leisure are suppressed. Marx observed this trade-off between productivity and leisure as well. He claims technology decisively favors the former over the latter because it embodies unequal property relations and emphasizes efficiency and exploitation:

If machinery is the most powerful means of raising the productivity of labour, i.e. of shortening the working time needed to produce a commodity, it is also, as a repository of capital, the most powerful means of lengthening the working day beyond all natural limits in those industries first directly seized on by it. It creates, on the one 
hand, new conditions which permit capital to give free rein to this tendency, and on the other hand, new incentives which whet its insatiable appetite for the labour of others.

(Marx 1867: 526; italics mine)

Since technology is designed and implemented to intensify productivity, labor becomes an integral part of this technical process. Accordingly, "it is animated by the drive to reduce to a minimum the resistance offered by man, that obstinate yet elastic natural barrier" (Marx 1867: 527). Insofar as labor is a commodity in this equation, it is subjected to the imperatives of this drive for improved productivity and increased profit. Such influence helps explain the outcome of the trade-off between productivity and leisure. For workers, the latter is foreclosed as a viable alternative because the system is organized by the imperatives of instrumental rationality. The conditions of work are thereby shaped by what Michel Foucault describes as "disciplines," or ever more refined modes of control, in the form of surveillance and normalization (Foucault 1975). Modern equivalents of these disciplines include unscheduled drug tests, task monitoring, and incentives for careerism that supplant preferences for leisure.

Suppose the claim of substantivism is true that technology embodies values that shape the ends of those agents using it. Under modern capitalism, these values objectify the environment and its inhabitants, subjecting it and them to increasingly instrumental modes of control. The members of the Frankfurt School developed and defended a "critical theory" along these lines, arguing that modern technology replaces the substantial values of humans conceived as social members with instrumental ones conceiving of them merely as producers and consumers. ${ }^{12}$ In these conditions, the social relations that are the inter-subjective conditions for substantive values are replaced with the technical imperatives of efficiency and profit. These effects are not mutually exclusive with the benefits that technology seems to provide, given that its widely touted benefits could just be further modes of control. Marcuse claims these benefits are thinly disguised countervailing effects that sustain and reproduce the ideology of "one-dimensional society" (Marcuse 1964: 12). The decrease of physical labor and increase of pleasure-seeking experiences create the conditions in which autonomy is reduced to the repetition of work and consumption. Even though technology improves the efficient allocation of resources and this enhances "welfare" (defined according to such values), the process negatively affects workers by decreasing opportunities for self-realization, self-respect, and solidarity. These values are sacrificed in the short run by the imperatives of technology, because the "creative destruction" of modern capitalism sells itself on the assumption that new, better opportunities for work are always created as part 
of this process. That is not always the case, however, though it might be sometimes (Uchitelle 2006: Ch. 3).

Since technical innovation has immediate and significant costs to workers' welfare, these costs ought to be weighed against any potential future benefits. Yet the anti-democratic organization of work frustrates the participation of workers to help determine their own fate where innovation and obsolescence are concerned. A seemingly innocuous example of the technical intensification of labor in this respect is the use of digital communication in our daily lives. The introduction of "smart" phones and tablets, and our tendency to rely on these seamless modes of interaction, expands the productivity of work beyond normal business hours. By and large, we have accepted the invasiveness of such devices on the basis of their efficiency so that the new normal is to work everywhere and at all times. Whether that is a benefit or a burden might seem like a question that is relative to an individual's preferences, but the real issue is whether workers get a substantial voice in how such technology is used. The fact that we have assimilated their use into our culture so quickly without much personal reflection or public debate is telling in this regard.

Finally, the intensification of labor merely precedes the next and final stage in the domination of technology over human beings. The present stage increases production with more efficient means, while the industrial destruction of the environment is reframed as "progress" for humankind. It is not just the resources of nature that are viewed as raw materials to serve the ends that are dictated by this form of rationality, but also workers themselves. They are used to create the goods and services that ensure the perpetual motion of the commodity machine, until they are replaced with more efficient machines in the form of computers, algorithms, and automated systems. In the earliest stage of industrialization, G.W.F. Hegel anticipated this outcome: "The abstraction of production makes work increasingly mechanical so that the human being is eventually able to step aside and let a machine take his place" (Hegel 1821: $\$ 198$ ). The ultimate effect of technology is obsolescence-replacing work with machines. While it raises obvious concerns about how workers will satisfy their welfare, the process does not end with the mere replacement of workers by machines. What may happen next is the subject of both dystopian science fiction and popular entertainment-the obsolescence not just of work, but also of workers themselves. In a pessimistic narrative that can be traced back to substantivism, the "rise of the machines" is the end game in which humans are either hunted down and eliminated or cultivated as batteries to power the machines. Perhaps these scenarios are merely the stuff of imagination, but serious questions remain: What will happen to humans when the level of technology that is achieved truly makes it possible to reduce the workday, or eliminate it altogether? What will happen to workers who are replaced with machines? How will they satisfy their welfare? 


\section{Kory P. Schaff}

\section{Basic Income and Inequality}

In this section, we shall examine the benefits of a basic income scheme with an emphasis on what makes it an appealing alternative for addressing the problem of inequality. In its conception, the idea is rather simple and elegant. All qualified individuals will receive a cash grant regardless of their employment history, income, or status. The grant is universal and unrestricted since all beneficiaries will receive the same amount and all of them are free to use it however they choose. ${ }^{13}$ In addition, basic income is often defended as viable policy for ensuring a social minimum that avoids some of the problems of traditional welfare policies. The idea of providing this social minimum in the form of a universal grant has increased in popularity in democratic welfare states for this reason. ${ }^{14}$ This idea is appealing to both right- and left-leaning theorists and policymakers alike for the following reasons: On one the hand, libertarians argue that provision of a basic income eliminates the need for paternalistic welfare policies, enhances the buying power of consumers, and ultimately promotes economic growth. On the other hand, egalitarians claim it will address the problem of inequality by ensuring a social minimum for all regardless of contribution or status. The appeal of such a scheme across the traditional economic spectrum has also been spurred by the growth of a cottage industry advocating on its behalf, as well as political parties who have taken up its cause in the European Union and beyond..$^{15}$ As a result, dozens of states and local governments around the world from Finland to Bakersfield, CA, have created pilot programs to test the feasibility of a basic income scheme.

A basic income scheme has two major benefits when compared with traditional welfare measures. First, it promotes the value of liberty by allowing persons to choose what to do with their share of the grant. In doing so, it avoids the paternalism of traditional welfare policies, which often require the least well off to provide evidence of need by submitting their private lives to invasive state procedures. A basic income grant avoids this "means-testing" because one does not have to lack means to get it. The grant is paid to everyone regardless of means and no questions are asked about how or where it is used. This will obviously appeal to libertarians and liberals alike who reject paternalism in favor of individual liberty. Second, basic income also promotes the value of equality by subsidizing a more egalitarian distribution of resources arising from social cooperation. Rather than basing its distribution on income, in which the wealthy pay higher tax rates to provide resources that can be redistributed to the least well off, basic income provides a cash grant that all citizens are entitled to regardless of their contribution. As such, it avoids a familiar objection to the welfare state that "free riders" benefit from such policies without paying any of the costs. This objection looms large in the economics of envy and politics of resentment, fostering opposition to taxation and welfare 
assistance, and supporting a disturbing form of scapegoating that is currently resurgent in debates about immigration and sovereignty. ${ }^{16}$

For these reasons, Phillipe Van Parijs claims that a basic income scheme has the potential to reconcile the conflicting values of liberty and equality in democratic welfare states. His theory of "real-freedom-for-all" is based on the libertarian conviction that the efficiency of markets can be used to expand the liberal value of equality by providing a social minimum to all that avoids the objections just described. According to Van Parijs, the principle of "real-freedom-for-all" combines the formal freedom of negative liberty to do as one pleases (short of coercion or harm to others), with an all-purpose means for realizing the ends of positive liberty. Subsequently, he advocates granting all citizens an equal share of a bundle of resources consistent with "security" and "self-ownership" (Van Parijs 1995: 33). In effect, this libertarian approach avoids the problem of redistributing downward by "taking from the rich and giving to the poor" and retains the egalitarian commitment to the value of equality. All beneficiaries can use these means for whatever purpose they want. Some examples that may help reduce inequality include buying insurance against sickness or unemployment, giving the grant to charity, supplementing consumption habits, and working less to take more leisure. An obvious attraction of basic income, then, is its practical flexibility. The cash grant can be used in diverse ways, many of which will contribute to economic growth that, in turn, could increase the amount of the grant over time.

A relevant feature of Van Parijs's proposal here is that basic income can, in principle, reduce the now dominant reliance on work. He claims that one way it splits the difference, so to speak, between capitalism and socialism is it displaces work as the primary requirement for a social minimum. A problem with that displacement, however, is it does not fit neatly (not yet, anyway) with the normative principle in capitalism that reward ought to be a product of contribution. For this reason, it "differs from a social insurance scheme to the extent that its beneficiaries need not have contributed to it out of their past earnings in order to be entitled to benefit from it" (Van Parijs 1995: 34). While Van Parijs stresses the compatibility of basic income with the values of liberty and equality, the ideal of this policy does not actually fit well with a central tenet of both capitalism and socialism, namely, reciprocal contribution and reward. One relevant objection here is that individuals will opt out of working altogether as the amount of the grant increases:

The real freedom to accept a low-paid job one would like to take, whether because of its intrinsic appeal or because of the training or experience it provides, is unambiguously increased as the level of the unconditional income goes up. 
The more their income is supplemented by the grant, the more likely it is that individuals will opt out of full-time work and perhaps even work altogether, preferring instead to be surfers who are fed by the productive contribution of others.

The worry here is that basic income's effect on work can undermine its efficacy and success at reconciling the values of liberty and equality. Insofar as the cash grant diminishes the necessity of work and pushes its value in the direction of freely undertaken labor, it can lead to economic inefficiencies. With the right mix of incentives that larger amounts of the grant would induce, it has the potential to undercut productive contribution over time as workers leave the labor market altogether. In turn, this will decrease the total value of resources to be distributed, thereby leading to a decrease in the amount of the grant over time. One endemic feature of capitalism that makes this problem more likely is the boom-bust cycle and its relation to unemployment. When the market is booming and unemployment is low, the amount of the grant will be higher and may induce individuals to reduce their work hours for more leisure time. But when the market is a bust and unemployment is high, the amount of the grant will be lower, even though individuals will likely rely on it to make up for lost income. In this scenario, the cost of keeping the grant at pre-recession levels will increase along with the political pressure to do so, but the economics of doing so are murky and hard to predict.

There are other technical difficulties that face the success of a basic income scheme as well. For example, whether the grant is paid in full annually or provided by regular installments can change some of the complexities we have been discussing. While one or the other might be more or less efficient economically, paying the grant out in equal installments could lead to a paternalist effect on the choices of beneficiaries, something the proposal is supposed to avoid (Van Parijs 1995: 46-47). Another problem that faces the "universal" feature of a basic income grant is that of capabilities and disadvantage. An equal share of resources provided to all in the form of a grant cannot achieve the egalitarian aim of equalizing the net benefits accrued by it where moral luck is concerned. As Amartya Sen claims, individuals with a lower threshold of functioning require a larger share of resources to translate functioning into capabilities (Sen 1992). For individuals with physical disabilities, a greater share of resources is required in order to achieve the same level of capability as the able-bodied. In this respect, the "universal" feature of a basic income grant may have to be modified more to address the complexities of "difference" as a critical normative consideration of equality. ${ }^{17}$ These problems might raise some doubts about the ethical and economic appeal that basic income offers, but they cannot be resolved here. At the very least, a basic income scheme warrants serious consideration and further research. 


\section{The Limits of a Basic Income in the Age of Automation}

So far, we have established that the instrumental and non-pecuniary benefits of work are a mixed picture at best. Under cyclical market conditions, these benefits are often turned into burdens by contingent forces beyond the control of workers. The income that work provides is a good thing if it is sufficient to satisfy needs and support life plans, but if not, or there is no work available, it becomes a serious burden. These same forces also influence the benefits of self-realization, self-respect, and community that work can provide, leading to jobs that are exploitative and coercive and that diminish autonomy. When the effects of technology are added to this picture, these burdens are intensified. To be sure, the advance of science and technology has had a significant impact on life. It is has decreased injuries, disease, and death, as well as improved our understanding of the universe and our place within it. Yet the benefits of technology do not necessarily improve working conditions for everyone. The domination of instrumental rationality leads to the intensification of labor and, in many cases, exacerbates its burdensome aspects.

What happens when basic income is added to the picture we have just described? At a glance, ensuring a social minimum for all citizens seems to be an elegant solution to some serious problems facing the democratic welfare state. With the cash provided by such a grant, workers can supplement their income and enjoy greater buying power, or reduce their work hours for more leisure time. Moreover, it has the potential to offset the harms caused by job loss and remove some of the stigma attached to unemployment and welfare assistance. Although it can augment the financial benefits of work in these respects, by itself a basic income grant cannot replace self-realization, self-respect, and community. In line with Van Parijs's slogan of "real-freedom-for-all," one might object that providing individuals with these means is an optimal way to help individuals to realize their ends. A basic income guarantees a flexible form of support that can support any and all values in this respect. However, before giving up altogether on the non-pecuniary benefits that work offers, it is worth considering some limitations of basic income.

First, it seems that a basic income scheme will have little effect on reducing inequality. While it augments the income of beneficiaries, and this sounds like good policy especially for struggling low-income earners, this does not reduce inequality. One reason it will have little effect in this respect is that the grant is paid out in an equal amount to everyone, so its effects on the distribution of income will actually be nil. The concentration of wealth and the growing income gap is a significant problem that should give us pause. For example, the three richest individuals in the United States together own more than $50 \%$ of its income earners, which is $63 \%$ of American households, or 160 million workers (Kirsch 2018). Those numbers are staggering and suggest more needs to be done 
to constrain the typical unequal distribution of wealth. A basic income scheme tries to avoid the problems associated with redistributive policies, but for this reason, it is not well designed to constrain the growth of inequality. Putting a social minimum in place may improve the welfare of the least well off to be sure, but it seems inequality will remain relatively unchanged and that is concerning.

Second, the provision of a basic income grant augments the income of individuals to satisfy needs and support their life plans. In effect, it will likely be used for more consumption, which can have social and environmental consequences. One social effect of increasing consumption is that inequality will be exacerbated. As Shor notes about current debates among policymakers, there is a consensus the problem of inequality can be solved "by getting more income into more people's hands" (Schor 2000: 5-6). She takes exception to this view because the goals of redistribution and growth are insensitive to the fact that consumption is part of the problem. Schor claims that the solution of more income "leads to consumption practices that exacerbate and reproduce class and social inequalities, resulting in, and perhaps even worsening, an unequal distribution of income" (Schor 1991: 6). This is driven by the features of what she calls "new consumerism" that perpetuate the upscaling of lifestyle norms, spending beyond the relative means of one's income, and consuming luxury goods that are branded as status symbols. Given these trends, putting more cash in the hands of consumers will exacerbate inequalities, especially for low-income households and communities of color. Thus, basic income may unwittingly make the distribution of inequality worse off by giving individuals the freedom to spend the grant how they want. Since most individuals have shown themselves to be irrational consumers for the most part, giving them more unrestricted income will simply contribute to the problem of inequality.

Another social effect that a basic income scheme may have is a diminished sense of community. In the absence of work, and without a sense of worth that accompanies engaging with others to achieve a common purpose, a basic income will leave individuals without a major source of social interaction. There are other venues that may replace lost work in this respect, but whether these offer self-realization, self-respect, and community with a common purpose is unclear. One reason why is that these benefits depend on standing in social relations with others, while lacking work undercuts the ability of one to stand in such relations. After losing their jobs, individuals report feeling more isolated and getting less enjoyment out of their daily activities (Uchitelle 2006). It is true that work is not the only context in which social relations provide support for doing productive activities, gaining a sense of worth, or engaging with others in a common purpose. However, for most workers, it is clearly a significant form of such support. If machines replace jobs and entire industries are 
automated, the elimination of social relations found in workplaces will almost certainly diminish a sense of community. Whether that can be replaced by other social relations, or how quickly that process of adjustment will take, is an empirical question that cannot be answered here.

Finally, a basic income grant that increases income and consumption raises worries about the environmental limits of welfare policies that are based exclusively on economic growth. There is a serious concern among scientists that the rapid growth of industrialization over the last century, which is predicated on burning fossil fuels, has already pushed the planet past its tipping point in the direction of massive and inhospitable climate changes. We are looking at a future planet that will be significantly warmer, with more intense weather events, diminished natural resources, and significantly larger populations requiring more resources to satisfy welfare. Schor claims there can be no common solution to these problems without addressing the underlying patterns of consumption that feed them:

[I]t is difficult to make an ethical argument that people in one of the world's richest countries need more when the global income gap is so wide, the disparity in world resource use so enormous, and the possibility that we are already consuming beyond Earth's ecological carrying capacity so likely.

(Schor 2000: 7)

Under these circumstances, a basic income scheme is more likely to contribute to the problem of consuming beyond our ecological limits by providing a grant to individuals that immediately boosts their buying power as consumers. Perhaps basic income can be part of a solution to these problems by encouraging workers to reduce work hours, take more leisure time, and engage in sustainable forms of consumption. However, in an age of automation where many workers are likely replaced by machines, and where goods and services can be produced more efficiently, it is hard to predict what they would do with their time and money. If we already spend most of our time working in order to consume, as Schor ably shows, it seems that a sudden increase in unstructured time brought on by part-time work or unemployment will be filled by consuming more of those goods and services. That is not an outcome either the planet or future generations can afford.

What is to be done? The question remains an open-ended one. At the very least, the current debate about basic income and the need for a social minimum pushes us to answer the question. When we also consider the benefits and burdens of work, the effects of automation on the future of work, and the viability of basic income in this context, it is clear that democratic welfare states need to develop new strategies for resolving the problems that are endemic to them. 


\section{Notes}

1. An early version of this argument is made by Rifkin (1995), and an insightful economic history of technology and obsolescence can be found in Slade (2007). A recent review of technical developments can be found in Wired, "A.I. and the future of work" (2018).

2. For studies of these themes in ancient Greek thought, see Meiksens Wood (1997) and Murphy (1993). The idea of work as punishment in the thought of St. Augustine is described in Kidwell (2013).

3. In its conception, the self-realization argument is a version of Marx's argument about alienated labor. He claims that the "species-being" (Gattungswesen) of human beings is social labor, and under capitalism the form this labor takes alienates individuals from this essential nature (Marx 1844: 58-68; Brudney 1998: Ch. 4).

4. I am not suggesting it is impossible for individuals without work to have self-respect, but as studies of the consequences of unemployment show, selfrespect suffers from the lack of work in most contexts.

5. A critique of the skilled/unskilled distinction can be found in Crawford (2009: Ch. 2).

6. A good review of the literature on the psychological and physiological harms of unemployment and joblessness can be found in Uchitelle (2006: Ch. 8).

7. See Warren, Thompson, and Saegert (2001: Ch. 1).

8. The most comprehensive discussion of these concepts can be found in Wertheimer $(1987,1996)$.

9. The costs and benefits of vertical work organization are reviewed by McPherson (1983), Bowles and Gintis (1993), Schweickart (2002), Schaff (2012), and Anderson (2017).

10. For a recent defense of a right to work as fair conditions of employment, see Schaff (2017).

11. This statement is often mistakenly attributed to Adam Smith, but it is actually a slogan used by the New England Council, a regional chamber of commerce, which President John F. Kennedy appropriated and first used in a speech in 1963.

12. This is the basis of Jürgen Habermas's claim that the "life-world," which grounds the communicative action and inter-subjective relations of rational agents, is eclipsed by a "system" of instrumental and technological domination (Habermas 1985).

13. One problem that is not addressed here is the question of who qualifies for basic income. Most theorists and policymakers advocate for it on the assumption that citizenship is the proper category for the benefit, but the presence of migrant workers and undocumented immigrants in market economies, whether they contribute or not, complicates this question. For a review of this question, see Bay and Pedersen (2006).

14. There is a historical pedigree to basic income. Rawls mentions the so-called negative income tax in this respect, which was a popular topic of policy discussions in the 1970s following the Great Society programs. Ideally, this policy would involve a systematic transfer of resources through a reverse income tax that progressively pays greater compensation to the least well off (Rawls, 243).

15. Examples include Basic Income Earth Network (BIEN), US Basic Income Guarantee Network (USBIG), and Basic Income Canada Network, among many others.

16. While this phenomenon is not new historically, it has become resurgent in the form of misinformation and propaganda that led to Brexit in the United Kingdom and Trumpism in the United States.

17. See Anderson (1999) for a discussion of difference and equality in this respect. 


\section{References}

Anderson, E. 1999. "What Is the Point of Equality?” Ethics 109(2): 287-337.

Anderson, E. 2017. Private Government: How Employers Rule Our Lives (and Why We Don't Talk About It). Princeton: Princeton University Press.

Arneson, R. 1993. "Democratic Rights at the National and Workplace Level." In The Idea of Democracy. Cambridge: Cambridge University Press.

Bay, A. and Pedersen, A. 2006. "The Limits of Social Solidarity: Basic Income, Immigration and the Legitimacy of the Universal Welfare State." Acta Sociologica 49(4): 419-436.

Bowles, S. and Gintis, H. 1993. "A Political and Economic Case for the Democratic Enterprise." Economics and Philosophy 9: 75-100.

Breckman, W. 1999. Marx, The Young Hegelians, and the Origins of Radical Social Theory. Cambridge: Cambridge University Press.

Brudney, D. 1998. Marx's Attempt to Leave Philosophy. Cambridge, MA: Harvard University Press.

Crawford, M. 2009. Shopclass as Soul-Craft: An Inquiry Into the Value of Work. New York: Penguin Books.

Elster, J. 1988. "Is There (or Should There Be) a Right to Work?" In Democracy and the Welfare State. Princeton: Princeton University Press.

Ezorksy, G. 2007. Freedom in the Workplace? Ithaca, NY: Cornell University Press.

Feenberg, A. 2002. Transforming Technology: A Critical Theory Revisited. Oxford: Oxford University Press.

Foucault, M. 1975. Discipline and Punish: The Birth of the Prison. New York: Vintage.

Habermas, J. 1985. The Theory of Communicative Action, Vol. 2: Lifeworld and System. Boston: Beacon Press.

Hegel, G.W.F. 1821. Elements of the Philosophy of Right. Cambridge: Cambridge University Press.

Kidwell, J. 2013. "Labour in St. Augustine." In Oxford Guide to the Historical Reception of Augustine, 779-784. Oxford: Oxford University Press.

Kirsch, N. 2018. "The 3 Richest Americans Hold More Wealth Than Bottom $50 \%$ of the Country, Study Finds." Forbes Magazine. www.forbes.com/sites/ noahkirsch/2017/11/09/the-3-richest-americans-hold-more-wealth-than-bot tom-50-of-country-study-finds/\#2997688c3cf8

Levine, A. 2001. "Fairness to Idleness: Is There a Right Not to Work?" In Philosophy and the Problems of Work. Lanham, MD: Rowman and Littlefield.

Marcuse, H. 1964. One-Dimensional Man: Studies in the Ideology of Advanced Industrial Society. Boston: Beacon Press.

Marx, K. 1844. "The Economic and Philosophical Manuscripts." In Selected Writings. Indianapolis: Hackett Publishing.

Marx, K. 1867. Capital, Vol. I. New York: Penguin Press.

McPherson, M. 1983. "Efficiency and Liberty in the Productive Enterprise: Recent Work in the Economics of Work Organization." Philosophy and Public Affairs 12(4): 354-368.

Meiksens Wood, E. 1997. Peasant-Citizen and Slave: The Foundations of Athenian Democracy. New York: Verso.

Murphy, J.B. 1993. The Moral Economy of Labor: Aristotelian Themes in Economic Theory. New Haven: Yale University Press.

Nozick, R. 1974. Anarchy, State, and Utopia. New York: Basic Books. 


\section{Kory P. Schaff}

Pikkety, T. 2014. Capital in the Twenty-First Century. Cambridge, MA: Harvard University Press.

Pollin, R. and Luce, S. 2000. The Living Wage: Building a Fair Economy. New York: New Press.

Rawls, J. 1999. A Theory of Justice (Rev ed.). Cambridge, MA: Harvard University Press.

Rifkin, J. 1995. The End of Work: The Decline of the Global Labor Force and the Dawn of the Post-Market Era. New York: Putnam Publishing.

Schaff, K. 2012. "Democratic Rights in the Workplace.” Inquiry 55(4): 386-404.

Schaff, K. 2017. “A Right to Work and Fair Conditions of Employment.” In Fair Work: Ethics, Social Policy, Globalization. London: Rowman and Littlefield.

Schor, J. 1991. The Overworked American: The Unexpected Decline of Leisure. New York: Basic Books.

Schor, J. 2000. “The New Politics of Consumption.” In Do Americans Shop Too Much? Boston: Beacon Press.

Schweickart, D. 2002. After Capitalism. Lanham, MD: Rowman and Littlefield.

Sen, A. 1992. Inequality Reexamined. Cambridge, MA: Harvard University Press. Singer, B. and Ryff, C. 2001. “The Influence of Inequality on Health Outcomes.” In New Horizons in Health: An Integrative Approach. Washington, DC: National Academies Press.

Slade, G. 2007. Made to Break: Technology and Obsolescence in America. Cambridge, MA: Harvard University Press.

Smith, A. 1776. An Inquiry Into the Nature and Causes of the Wealth of Nations. Chicago: University of Chicago Press.

Uchitelle, L. 2006. The Disposable American: Layoffs and Their Consequences. New York: Alfred Knopf Publishing.

Van Parijs, P. 1995. Real Freedom for All: What (if Anything) Can Justify Capitalism. Oxford: Oxford University Press.

Warren, M., Thompson, J., and Saegert, S. 2001. "The Role of Social Capital in Combatting Poverty." In Social Capital and Poor Communities. New York: Russell Sage Foundation.

Weber, M. 1930. The Protestant Ethic and the Spirit of Capitalism. New York: Routledge.

Wertheimer, A. 1987. Coercion. Princeton: Princeton University Press.

Wertheimer, A. 1996. Exploitation. Princeton: Princeton University Press.

Wired.2018. A.I. and the Future of Work. www.wired.com/wiredinsider/2018/04/ ai-future-work/

Zimmerman, D. 1981. "Coercive Wage Offers." Philosophy and Public Affairs 10(2): 122-145. 